\title{
Processing of Titanium Porous Bodies by Foaming of Gelled Aqueous Suspensions of Powders
}

\author{
Z. Gonzalez (Instituto de Cerámica y Vidrio, CSIC, c/Kelsen 5, 28049, Madrid, Spain)
}

E. Molero (Instituto de Cerámica y Vidrio, CSIC, c/Kelsen 5, 28049, Madrid, Spain)

A. J. Sanchez-Herencia (Instituto de Cerámica y Vidrio, CSIC, c/Kelsen 5, 28049, Madrid, Spain)

B.Ferrari (Instituto de Cerámica y Vidrio, CSIC, c/Kelsen 5, 28049, Madrid, Spain)

\begin{abstract}
Use of porous titanium (Ti) and Ti alloys in orthopedic implants or in light structures requires processing routes that could generate an as-much-as possible control in the pores amount, shape, size and connectivity. In this work, a colloidal approach to the processing of Ti porous structures by the inside foaming of a porogen into a gelled high solid content aqueous suspension of Ti powders, is presented. The prepared slurries contained different amounts of Methyl Cellulose (MC) as gelling agent $(8,10$ and $12 \mathrm{~g} / \mathrm{L}$ ) and ammonium bicarbonate (BA) as porogen (15, 20, $25 \mathrm{wt}$. \%). The gel-casted samples were heated at mild temperatures ranging $\left(60,70\right.$ and $\left.80^{\circ} \mathrm{C}\right)$ to promote the gelation and produce, at the same time, the porosity by the thermal decomposition of the ammonium bicarbonate. Different structures are obtained depending on the combination of the study variables
\end{abstract}

\section{Keywords}

Powder, bio compatibility

\section{Introduction}

The high biocompatiblility, as well as the excellent mechanical and chemical stability of the Ti-based materials generate interest in the biomedical field, being usually employed for bone prosthesis and replacements [1]. However, to get effective fixation between Ti material and the natural bone, the piece must fulfill specific porosity requirements in order to have interactions with proteins (pores lower than 1 $\mu \mathrm{m}$ ) and cells (between $1 \mu \mathrm{m}$ and $20 \mu \mathrm{m}$ ) or to produce vasculogenesis processes (between $100 \mu \mathrm{m}$ and $1000 \mu \mathrm{m})[2-4]$.

Recently, the interest for the development of new approaches for powder metallurgy processing of $\mathrm{Ti}$ particles and its alloys has grown considerably due to possibility of reducing the processing costs and manufacturing time. Although the conventional methods, based on cold pressing and rapid sintering techniques, such as spark plasma sintering (SPS), or microwave sintering (MWS) [3] have shown effectiveness to reduce the grain size and improve the mechanical properties of the shaped materials, they present important drawbacks for not being suitable for the production of components with Near Net Shape (NNS) [5].

On the other hand, colloidal processing techniques have confirmed to be an alternative tool to overcome the low compressibility of Ti powders. The surface of Ti particles passivizes in aqueous suspensions and the oxygen content does not increase with the lower grain size than that achievable with conventional powder metallurgic (PM) methods [6]

This work presents the processing of Ti porous materials from a colloidal approach based on a thermal gelation process. The use of water and additives coming from the food industries makes the process transferable to the industry with minor economic and environmental cost. The control on some variables of the gelling process, such as gelling agent and porogen concentrations or the gelation temperature allow obtaining samples with a wide variety of porous structures which could be good candidates for different biomedical applications.

\section{Experimental}

The raw materials used herein were metallic Grade $1 \mathrm{Ti}$ fabricated by plasma spray under inert atmosphere (AP\&C Inc., Canada) with an average particle size of $10 \mu \mathrm{m}$, ammonium bicarbonate (BA, $\mathrm{NH}_{4} \mathrm{HCO}_{3}$ ) used as pore former and purchased with analytical grade from Panreac, while the methyl 
cellulose of $\approx 4000 \mathrm{mPa} \cdot \mathrm{s}$ of viscosity (MC, Dow Chemicals) was used as shaping additive Polyethyleneimine (PEl, Mw 25,000 mol/g Sigma-Aldrich) was used as dispersant and Tetramethylammonium hydroxide ( $\mathrm{TMAH}, \mathrm{C}_{4} \mathrm{H}_{13} \mathrm{NO}$ ) was employed to adjust the $\mathrm{pH}$ of slurries. All these chemicals were used of reagent grade and without any further purification.

The aqueous slurries for gelling experiments were prepared by dissolving the $M C$ in a specific amount of DI water, where a further amount of the dispersant was previously added at a pH value of 9. Over this basic solution the ammonium bicarbonate was also dissolved to later on add the as-received Ti powder. All these mixtures were carried out with the aid of a pitched blade stirrer and the resulting slurries were later ball milled in a in a plastic jar with alumina balls for 2 hours.

Rheological measurements of the slurries were recorded using a Haake Mars II rheometer and a double cone-plate measuring geometry. Tests were performed working on control stress mode (CS) and control rate $(\mathrm{CR})$ modes. For CS mode tests the stress was increased from 0 to the desired value and back to $0 \mathrm{~Pa}$ at up and down rate of $2 \mathrm{~Pa} / \mathrm{min}$. In the case of $\mathrm{CR}$ tests shear rate was increased up to $1000 \mathrm{~s}^{-1}$ in 120 seconds, keep at $1000 \mathrm{~s}^{-1}$ for 60 seconds and decreased to $0 \mathrm{~s}^{-1}$ in 120 seconds. Viscosity values were obtained from the flow curves of the prepared suspensions.

Porous pieces were fabricated by pouring the slurries into flexible silicone molds and heating them in a chamber with forced convection at temperatures ranging between 50 and $60^{\circ} \mathrm{C}$ until all the water was evaporated. The consolidated porous green samples were then cooled down to room temperature and demolded. Scanning electron microscopy (SEM) observations were made for porous microstructures (Hitachi TM-1000, Japan). Apparent densities of the shaped samples were calculated geometrically and pore volume and size distribution were determined by Mercury Intrusion Porosimetry (MIP) using a Micromeritics AutoPore IV 9510 (USA)

\section{Results}

The role of the MC in the thermal gelation of the samples was essential due to the gel formation at a specific temperature (gelation temperature) by the physical crosslinking of their polymer chains. This produced a significant change in the viscosity of suspensions which resulted in a viscoelastic liquid, serving as a guide to the compaction of the particles and the shaped material. The result of the gelation process was the uniform and homogeneous distribution of particles embedded in the gel network. In addition, the decomposition of the $\mathrm{BA}$ at the gelation temperature produced $\mathrm{CO}_{2}$ which acted as the porogen. Figure 1 shows the scheme of the Ti porous framework proposed in this work. The MC polymerized at a low temperature $\left(<100^{\circ} \mathrm{C}\right)$, forming a polymeric framework that immobilized the $\mathrm{Ti}$ particles and simultaneously retained the gas bubbles during the compaction of the piece.

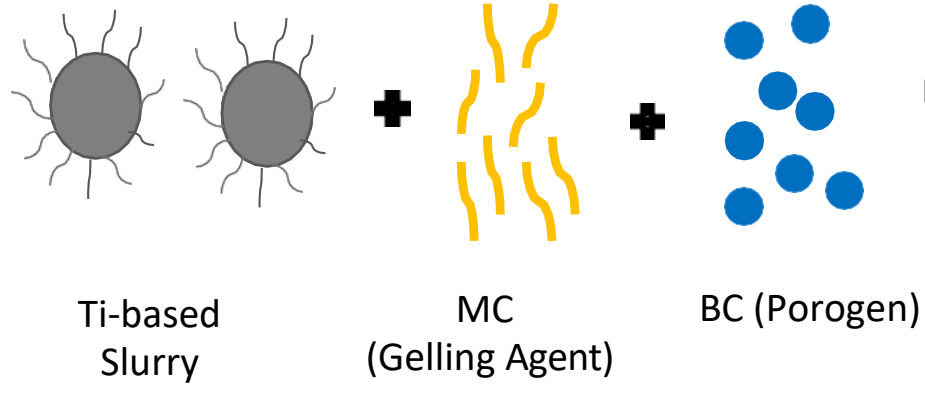

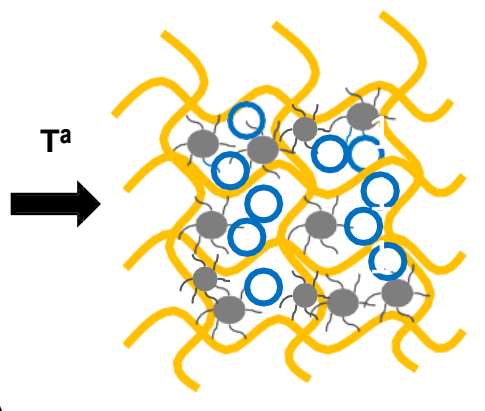

Porous

Framework

Figure 1. Scheme of the slurry with $M C$ as gelling agent and $B C$ as porogen

Based on previous works [6,7], the dispersion and stabilization conditions of Ti powders in aqueous media was used. A solid content of 50 vol.\% prepared with $1 \mathrm{wt} . \%$ of PEI as dispersant was selected to formulate of the Ti slurries. The Krieger Dougherty's rheological model showed that using a cationic polyelectrolyte, such as $\mathrm{PEI}$, the values of maximum packing density were as high as $74 \%$. Thus, this composition was also used to study the rheological behavior of the slurries with the addition of gelling agent and pore former. The presence of the MC determines the polymerization degree and the gel structure during the shaping process, being also the responsible of changes in the viscosity of the suspensions, the rheological behavior was analyzed after each addition. Figure 2 shows a comparison of the flow curves for slurries of Ti without MC or BA, with an aqueous media containing $10 \mathrm{~g} / \mathrm{L}$ of $\mathrm{MC}$ 
and with an aqueous media containing $10 \mathrm{~g} / \mathrm{L}$ of $\mathrm{MC}$ and $20 \mathrm{wt} . \%$ of $\mathrm{BA}$.

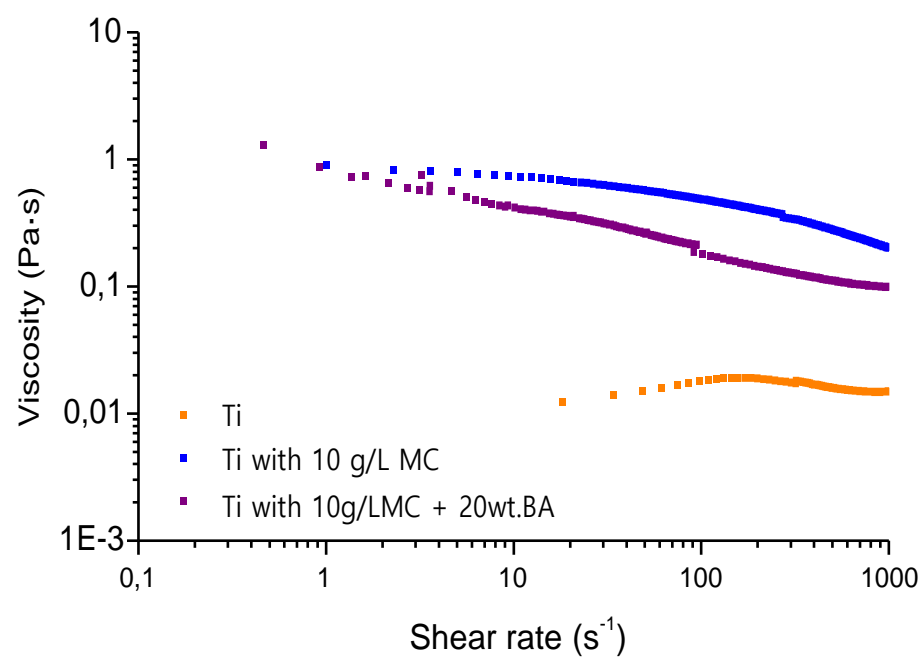

Figure 2. Flow curves of Ti slurries with 50 vol. \% of solids contents without methylcellulose (MC), with $10 \mathrm{~g} / \mathrm{L}$ of $\mathrm{MC}$ and with10 $\mathrm{g} / \mathrm{L}$ of $\mathrm{MC}$ and $20 \mathrm{wt}$. \% of BA.

The initial suspension of the Ti particles stabilized with $1 \mathrm{wt} . \%$ of PEI, and with a solid content of 50 vol.\% presented a quasi-Newtonian behavior with moderate viscosity values between 10-20 mPas ${ }^{-1}$. Nevertheless, as expected, the addition of the $M C$ increased significantly the viscosity values, being this raise higher at the low shear rates. Moreover, the addition of the gelling agent and the porogen resulted in a decreasing on the viscosity values with the increment of shear rate indicating a pseudoplastic behavior. This means that both suspensions presented high values of zero-shear viscosity which is indicative of the capacity of samples to keep the shape and avoid segregation of phases out of external forces or stirring. Besides, the values of viscosity obtained, $100-1000 \mathrm{mPas}^{-1}$, at shear rates between 10-100 s $\mathrm{s}^{-1}$ were appropriate to allow the suspensions handling and their processing by casting in noporous molds.

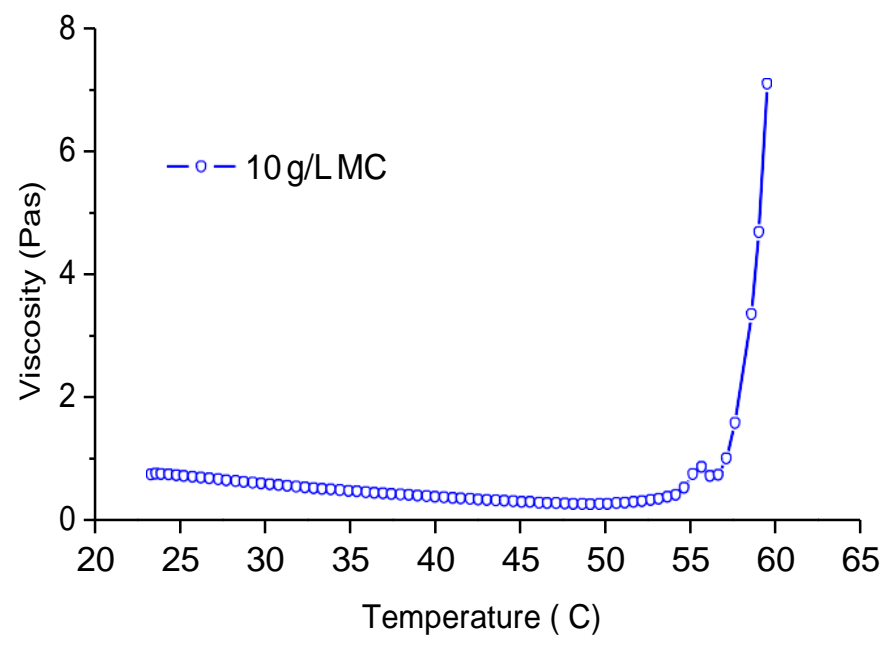

Figure 3. (a) Viscosity values vs temperature for the suspensions at $50 \%$ vol. with $10 \mathrm{~g} / \mathrm{L}$ of MC

On the other hand, in order to study the gelation temperature of the MC used herein, the variation of the viscosity (at a shear rate of $10 \mathrm{~s}^{-1}$ ) with the increase of temperature was plotted in figure 3 . For this analysis, a Ti suspension with an aqueous media containing $10 \mathrm{~g} / \mathrm{L}$ of $\mathrm{MC}$ was measured. 
The plot presented two differentiated sections. One at low temperature, where the viscosity decreased with the raise of temperature, typical of ceramic/metal slurries stabilized with polyelectrolytes [8][9]. And other above $50^{\circ} \mathrm{C}$, where the viscosity increased with the gelling process of $\mathrm{MC}$, which occurs during heating due to the hydrophobic association between methyl groups on cellulose chains [10][11]. When the temperature was between $52-57^{\circ} \mathrm{C}$, the viscosity increased exponentially, which is attributed as gelation temperature [12]. All the previous results showed that a temperature over $57^{\circ} \mathrm{C}$ induces increment in viscosity of the fluid slurries and the $\mathrm{MC}$ is able to keep the internal structure of the material. Besides, the addition of BA to as a gas porogen produces the pores formation at the same time that temperature increases the viscosity, leading to stable pores inside the final sample.

To complete the study about the gelling process of the Ti powders, some process variables, such as gelling agent and porogen concentrations or gelation temperature were analyzed. For this, the amount of MC, BA and the temperature in the stove was varied respectively as follow: 8,10 and $12 \mathrm{~g} / \mathrm{L}, 15,20$ and 25 wt. $\%$ and 60,70 and $80^{\circ} \mathrm{C}$. Figure 4 shows the pictures of some of the shaped samples made by combining of the amounts of $\mathrm{MC}$ and $\mathrm{BA}$ at different gelation temperature.

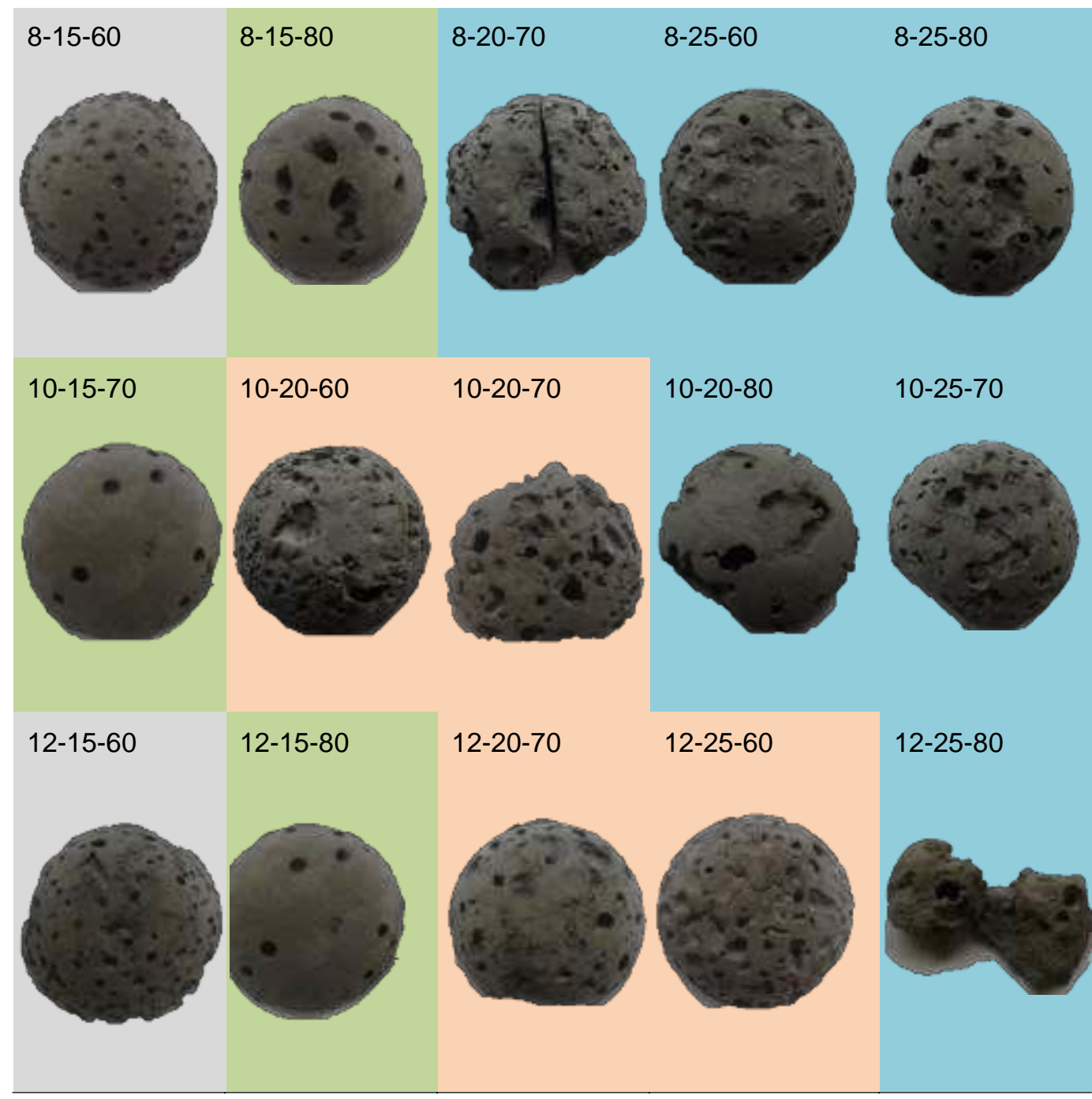

Figure 4. Images of the shaped samples made by combining the variables of the process. The amounts of MC and BA and the gelation temperature used in each experiment are showed up of each image.

Four different structures were identified: type A (in gray) corresponds to the lowest conditions of the study variables, in which closed pores are observed on the samples surface. An increase of the gelling agent concentration and temperature result in larger, tubular and directed pores, which are identified as type B (green). The type C (orange) corresponds to the average conditions for the process variables 
where the samples display a greater number of pores of average size, distributed homogeneously throughout the surface of each sample. And finally, type D (blue) represents the highest conditions of the study variables which produce a low level of consistency for the resulting structures. All of these samples have been characterized elsewhere [13] by measuring the viscosities of the suspensions, the apparent densities and pore size distributions values. In that work, the data have been also treated mathematically by a second-order polynomial function with a view to identifying the optimum operating conditions of the gelling process.

\section{Conclusions}

Ti powder was stabilized and dispersed in aqueous media with a 1 wt.\% of PEI. The formulation of the suspensions with $\mathrm{MC}$ as a gelling agent and BA as a porogen modified the rheological behavior producing an increment on the viscosity values and developing a pseudo-plastic behaviour where the viscosity values decrease with the increase of the shear rate. The temperature increment of the gelcasted suspensions above $57^{\circ} \mathrm{C}$ promoted at the same time the gas formation and the suspension gelling trapping the gas bubbles and leading to green porous structures. The variation of the amount of $\mathrm{MC}$ and $\mathrm{BA}$ or the modification of the gelation temperature resulted in a wide variety of structures with different types of porosities which could be susceptible to be used for different biomedical applications.

\section{Acknowledgements}

The authors acknowledge the financial support from the Spanish Ministry of Economy and Competitiveness and the European Fund for Regional Development through the projects MAT201570780-C4-1-P (MINECO/FEDER), and the Regional Government of Madrid through the program MULTIMAT-CHALLENGE, ref. S2013/MIT-2862, cofounded by FEDER. Z. Gonzalez acknowledges MINECO through the grant IJCI-2016-28538.

\section{References}

[1] A.P. Rubshtein, E.B. Makarova, D.G. Bliznets, A.B. Vladimirov, Properties of biocomposites based on titanium scaffolds with a different porosity, Bull. Mater. Sci. 40 (2017) 453-457.

[2] Zhao, Y., et al., Significance of powder feedstock characteristics in defect suppression of additively manufactured Inconel 718. Additive Manufacturing, 2020: p. 101277.

[3] A.J. Salinas, M. Vallet-Regí, G. Lusvardi, G. Malavasi, L. Menabue, M. Vallet-Regi, M. Edén, N. García-Honduvilla, P. Esbrit, J. Buján, P. Esbrit, Bioactive ceramics: from bone grafts to tissue engineering, RSC Adv. 3 (2013) 11116.

[4] Gao, X., et al., Numerical analysis of non-spherical particle effect on molten pool dynamics in laser-powder bed fusion additive manufacturing. Computational Materials Science, 2020. 179: p. 109648.

[5] E. Molero, B. Ferrari, A.J. Sanchez-Herencia, E. Gordo, P. Colombo, Ti/Ti3SiC2(/TiC) Bulk and Foam Composites by Pyrolysis of Polycarbosilane and $\mathrm{TiH} 2$ Mixtures, Adv. Eng. Mater. 2 (2017).

[6] R.G. Neves, B. Ferrari, A.J. Sanchez-Herencia, C. Pagnoux, E. Gordo, Role of stabilisers in the design of Ti aqueous suspensions for pressure slip casting, Powder Technol. 263 (2014) 81-88.

[7] E. Molero, A.J. Sanchez-herencia, R.G.D. Neves, E. Gordo, B. Ferrari, Shaping strategies for porous Ti fabrication throughout colloidal chemistry ., 2016.

[8] Wolff, S.J., et al., Experimentally validated predictions of thermal history and microhardness in laser-deposited Inconel 718 on carbon steel. Additive Manufacturing, 2019. 27: p. 540-551.

[9] A.J. Sánchez-Herencia, A.J. Millán, M.I. Nieto, R. Moreno, Gel-forming of nickel powders from aqueous slurries, Adv. Mater. 12 (2000) 1192-1195.

[10] Khairallah, S.A., et al., Laser powder-bed fusion additive manufacturing: Physics of complex melt flow and formation mechanisms of pores, spatter, and denudation zones. Acta Materialia, 2018. 108: p. 36-45.

[11] P.L. Nasatto, F. Pignon, J.L.M. Silveira, M.E.R. Duarte, M.D. Noseda, M. Rinaudo, Methylcellulose, a cellulose derivative with original physical properties and extended applications, Polymers (Basel). 7 (2015) 777-803.

[12] M. Knarr, R. Bayer, The shear dependence of the methylcellulose gelation phenomena in aqueous solution and in ceramic paste Dedicated to Dr. Walter Bayer on the occasion of his 90th birthday on January 4, 2014., Carbohydr. Polym. 111 (2014) 80-88.

[13] I. Gibson, D.W. Rosen, B. Stucker, 2015, Additive Manufacturing Technologies: 3D Printing, Rapid Prototyping, and Direct Digital Manufacturing, Springer, pp. 1-498. 